\title{
Efficacy of Umeclidinium/Vilanterol in Elderly Patients with COPD: A Pooled Analysis of Randomized Controlled Trials
}

\author{
Riju Ray ${ }^{1}$ (i) $\cdot$ Lee Tombs ${ }^{2} \cdot$ Michael J. Asmus ${ }^{1}$. \\ Isabelle Boucot ${ }^{3}$ (D) - David A. Lipson ${ }^{4}$ (I) $\cdot$ \\ Chris Compton $^{3} \cdot$ Ian Naya ${ }^{3}$
}

Published online: 27 June 2018

(C) The Author(s) 2018

\begin{abstract}
Objective The aim of this pooled analysis was to assess the efficacy and safety of umeclidinium/vilanterol (UMEC/VI) $62.5 / 25 \mu \mathrm{g}$ dual bronchodilation versus placebo in elderly symptomatic patients with chronic obstructive pulmonary disease (COPD).

Methods We conducted a post hoc pooled analysis of data from 10 randomized controlled trials (RCTs). Change from baseline $(\mathrm{CFB})$ in trough forced expiratory volume in $1 \mathrm{~s}$ $\left(\mathrm{FEV}_{1}\right)$, proportion of $\mathrm{FEV}_{1}$ responders $(\geq 100-\mathrm{mL}$ increase from baseline), and safety were analyzed in patients aged $<65, \geq 65$, and $\geq 75$ years on Days 28,56 , and 84 (12-week analysis of parallel-group design studies), Days 28, 56, 84, 112, 140, 168, and 169 (24-week analysis of parallel-group design studies), and Days 2, 42, and 84 (12-week analysis of crossover design studies).

Results The UMEC/VI intent-to-treat (ITT) populations comprised 2246, 1296, and 472 patients in the 12-week parallelgroup, 24-week parallel-group, and 12-week crossover analysis, respectively ( $\geq 65$ years: $36-44 \%$; $\geq 75$ years: $7-11 \%$ ).
\end{abstract}

Electronic supplementary material The online version of this article (https://doi.org/10.1007/s40266-018-0558-y) contains supplementary material, which is available to authorized users.

Riju Ray

riju.x.ray@gsk.com

1 US Medical Affairs, GSK, 5 Moore Drive, Research Triangle Park, North Carolina 27709, USA

2 Precise Approach Ltd, Contingent Worker on Assignment at GSK, Stockley Park West, Uxbridge, Middlesex, UK

3 Global Respiratory Franchise, GSK, Brentford, Middlesex, UK

4 Respiratory Research and Development, GSK, Collegeville, Pennsylvania, PA, USA
The placebo ITT populations comprised 528, 280, and 505 patients, respectively ( $\geq 65$ years: $37-41 \%$; $\geq 75$ years: 5-11\%). Significant improvements in trough $\mathrm{FEV}_{1}$ and significantly greater proportions of $\mathrm{FEV}_{1}$ responders were seen with UMEC/VI compared with placebo in all analyses regardless of patient age or timepoint considered $(p \leq 0.023)$, except Day 84 trough FEV ${ }_{1}$ CFB in the 12-week crossover analysis in patients aged $\geq 75$ years $(p=0.064)$. UMEC/VI safety profile was similar to placebo in all age groups.

Conclusions In this pooled analysis of RCT data, oncedaily UMEC/VI was well tolerated and provided clinically significant lung function benefits compared with placebo in younger and older patients with COPD.

Funding GlaxoSmithKline (study 208125).

\section{Key Points}

Compared with placebo, inhaled once-daily umeclidinium/vilanterol consistently and significantly improved lung function in elderly patients (aged $\geq 65$ and $\geq 75$ years of age) with symptomatic chronic obstructive pulmonary disease (COPD).

A significantly greater proportion of patients with symptomatic COPD experienced a clinically meaningful improvement in lung function ( $\geq 100$-mL improvement in forced expiratory volume in $1 \mathrm{~s}$ ) with inhaled umeclidinium/vilanterol compared with placebo in all age groups, with no notable diminution of effect with advancing age.

Inhaled umeclidinium/vilanterol therapy was well tolerated, with a safety profile comparable to that of placebo. 


\section{Introduction}

The global prevalence of chronic obstructive pulmonary disease (COPD) was $11.7 \%$ in 2010 [1]. COPD is principally a disease of older adults, and the prevalence is increasing due to aging population demographics [1-3]. In the US, it has been estimated that approximately one in ten people over the age of 75 years have COPD [4]. In Europe, the mean age of COPD patients is approximately 68 years old, with the majority $(\sim 70 \%)$ of patients with COPD classified as elderly ( $\geq 65$ years) [5, 6]. Multimorbidity increases with age [7], and older patients with COPD have a higher incidence of age-related comorbidities, such as diabetes mellitus, benign prostatic hyperplasia, cataracts, cardiovascular disease, hypertension, and dementia, compared with younger patients with COPD [6-10].

There is a paucity of data regarding COPD management in the elderly population [9]. Patients in randomized controlled trials (RCTs) of COPD medications are generally younger than the general COPD population seen in clinical practice [11, 12] and are less likely to have cardiac comorbidities [13]. Moreover, very few clinical trials $(\sim 1 \%)$ are conducted exclusively in elderly populations [14].

Older patients may not be included in clinical trials for a number of reasons; for example, they may be indirectly excluded due to increased levels of comorbidities or owing to the severity of these comorbidities, because of issues with obtaining reliable spirometry results, or owing to challenges in compliance with study procedures (e.g., inability to attend clinic visits as outpatients) $[15,16]$. Therefore, although elderly patients make up the majority of patients with COPD, the available RCT data may not fully reflect the efficacy and safety of pharmacological treatments for COPD in an elderly population.

Bronchodilators are the cornerstone of the pharmacological treatment of COPD [2]; however, the use of bronchodilators in elderly patients with COPD can be associated with a number of challenges. Elderly patients may find inhalers more difficult to use than younger patients and may have more impaired lung function, making them less able to generate the required inspiratory flow; these factors need to be taken into consideration when selecting an appropriate inhaler device for elderly patients $[4,17]$. Comorbidities in elderly patients may also affect their ability to use their device correctly [18]. Poor eyesight, impaired dexterity, arthritis in the fingers, and tremors can all affect a patient's ability to use an inhaler correctly [18], and patients with cognitive impairment may not take their medication as prescribed [19]. Comorbidities, poor adherence, or incorrect inhaler technique can in turn affect disease control, resulting in increased use of rescue therapies, as well as more frequent exacerbations, increased hospitalization, and worse outcomes [20-23]. In addition, age-related changes in physiology can result in a different pharmacokinetic or pharmacodynamic profile in older and younger individuals [24], which may lead to differences in adverse event (AE) profiles between the populations, further compounded by the potential for polypharmacy in older patients [25].

It is therefore important to demonstrate that COPD treatments are effective in elderly patients, and to understand their safety profile in this patient population. The fixed combinations of an inhaled long-acting muscarinic antagonist (LAMA) and a long-acting $\beta_{2}$-agonist (LABA) have proven efficacy for the treatment of COPD [26, 27], and are recommended in the Global initiative for Chronic Obstructive Lung Disease (GOLD) 2018 report for maintenance treatment of stable COPD [2]. The aim of the current pooled analysis was to compare the efficacy and safety of one such inhaled fixed LAMA/LABA combination, umeclidinium/vilanterol (UMEC/VI) $62.5 / 25 \mu \mathrm{g}$, with placebo in elderly patients with symptomatic COPD. Two cutoff points for the definition of 'elderly' were explored in this pooled analysis: those at least 65 and those at least 75 years of age.

\section{Methods}

\subsection{Study Design}

This study (GSK study number: 208125) was a post hoc pooled analysis of data from ten randomized studies that investigated UMEC/VI 62.5/25 $\mu \mathrm{g}$ inhaled once daily and were of at least 12 weeks' duration: GSK study DB2113360 (NCT01316900) [28], DB2113373 (NCT01313650) [29], DB2113374 (NCT01316913) [28], ZEP117115 (NCT01777334) [30], DB2114930 (NCT01817764) [31], DB2114951 (NCT01879410) [31], $\begin{array}{llll}\text { MID201211 (NCT02152605) [32], DB2114417 } & \text { [ }\end{array}$ (NCT01328444) [33], DB2114418 (NCT01323660) [33], and MID201317 (NCT02275052) [34] (Online Resource 1, see electronic supplementary material [ESM]). Data from all treatment arms were included in this analysis; however, only data for the comparison of UMEC/VI $62.5 / 25 \mu \mathrm{g}$ versus placebo are presented here. Three separate analyses were undertaken: a 24-week and a 12-week analysis of data from pooled parallel-group studies, and a 12-week analysis using data from pooled crossover studies. Four studies were included in the 24-week parallel-group integration analysis, seven in the 12-week parallel-group integration analysis (the four used in the 24-week integration analysis, plus three 12-week studies), and three in the 12-week crossover analysis (Online Resource 1, see ESM). 
In all studies, patients were eligible to participate if they were $\geq 40$ years of age with a diagnosis of COPD as per the American Thoracic Society/European Respiratory Society (ATS/ERS) definition [35], and were symptomatic either with or without a recent ( $\leq 1$ year) history of exacerbations (Online Resource 1, see ESM).

\subsection{Study Endpoints}

The primary efficacy endpoints of this pooled analysis were the change from baseline in trough forced expiratory volume in $1 \mathrm{~s}\left(\mathrm{FEV}_{1}\right)$ (assessed as absolute change and ratio of change over baseline value) and the proportion of trough $\mathrm{FEV}_{1}$ responders (patients achieving an increase of $\geq 100 \mathrm{~mL}$ above baseline in trough $\mathrm{FEV}_{1}$ ) on Days 28 , 56 , and 84 for the 12-week integration analysis of parallel design studies, Days 28, 56, 84, 112, 140, 168, and 169 for the 24-week integration analysis of parallel-group studies, and Days 2, 42, and 84 for the 12-week crossover analysis. Baseline $\mathrm{FEV}_{1}$ was defined as the mean of 30- and 5-min pre-dose measurements on Day 1. Safety endpoints included the pooled incidence of adverse events (AEs) in the UMEC/VI groups versus the placebo groups across the studies. Outcomes in the two pooled datasets (UMEC/VI and placebo) were analyzed in patients $<65$ and $\geq 65$ years of age, and those $\geq 75$ years of age.

\subsection{Statistical Analyses}

For the parallel design studies (DB2113360, DB2113373, DB2113374, DB2114930, DB2114951, MID201211, and ZEP117115), efficacy analysis was performed for the combined intent-to-treat (ITT) populations. One investigator site was excluded from the ITT population for study DB2113360 owing to significant deviations from good clinical practice. Absolute change in trough $\mathrm{FEV}_{1}$ for the 12- and 24-week parallel-group integrations was analyzed separately using mixed model repeated measures (MMRM) on each subgroup level with study, treatment, baseline $\mathrm{FEV}_{1}$, smoking status at screening, visit, visit by baseline $\mathrm{FEV}_{1}$ interaction, and visit by treatment interaction (where visit is nominal) as covariates. Ratios (\% change from baseline) of trough $\mathrm{FEV}_{1}$ change from baseline were analyzed using an MMRM on each subgroup level, with response of $\log$ (trough $\mathrm{FEV}_{1} /$ baseline $\mathrm{FEV}_{1}$ ) and covariates of study, treatment, smoking status at screening, log (baseline $\mathrm{FEV}_{1}$ ), visit, visit by $\log$ (baseline $\mathrm{FEV}_{1}$ ) interaction, and visit by treatment interaction. Results were back-transformed to provide point estimates for the ratios. For the 12-week parallel-group integration, the model used all available trough $\mathrm{FEV}_{1}$ values recorded on Days 28, 56, and 84 , and the 24-week parallel-group integration model used all available trough $\mathrm{FEV}_{1}$ values recorded on Days 28,
$56,84,112,140,168$, and 169 . For these two integration analyses, the proportion of trough $\mathrm{FEV}_{1}$ responders ( $\geq 100-\mathrm{mL}$ increase from baseline) was analyzed separately on each subgroup level using an MMRM for binary data with treatment, study, smoking status at screening, baseline $\mathrm{FEV}_{1}$, visit, visit by baseline $\mathrm{FEV}_{1}$ interaction, and visit by treatment interaction as covariates.

The analysis of the crossover design studies (DB2114417, DB2114418, and MID201317) was performed on the combined ITT population for all patients who received at least one dose of randomized study medication in a treatment period. This analysis used MMRM to assess 12-week trough $\mathrm{FEV}_{1}$, with covariates of period, period baseline $\mathrm{FEV}_{1}$, mean baseline $\mathrm{FEV}_{1}$, treatment, study, smoking status, visit, visit by period baseline $\mathrm{FEV}_{1}$ interaction, visit by mean baseline $\mathrm{FEV}_{1}$ interaction, and visit by treatment interaction (where visit is nominal). The model used all available trough $\mathrm{FEV}_{1}$ values recorded on Days 2, 42, and 84. The proportion of trough $\mathrm{FEV}_{1}$ responders $(\geq 100-\mathrm{mL}$ increase from baseline) in the crossover studies was analyzed using a separate generalized linear mixed model for each subgroup level and visit with treatment, study, smoking status at screening, period baseline $\mathrm{FEV}_{1}$, and mean baseline $\mathrm{FEV}_{1}$ as covariates. For all efficacy analyses, an investigation of the study by treatment interaction was conducted to assess homogeneity of effect.

Safety analyses were performed using the ITT population for all patients who received at least one dose of randomized study medication in a treatment period, and separately for the parallel design and crossover design studies.

All outcomes were reported according to the randomized treatment. Baseline $\mathrm{FEV}_{1}$ was summarized by treatment. Summary statistics for the absolute trough $\mathrm{FEV}_{1}$ and change from baseline in trough $\mathrm{FEV}_{1}$ at each clinic visit and for each treatment were reported. The least squares (LS) means and LS mean change from baseline values for each treatment group were reported with their associated standard errors (SE) or $95 \%$ confidence interval (CI). The estimated treatment difference along with corresponding 95\% CI and $p$-value for each visit were also presented, as well as the number $(\%)$ of patients who achieved a $\geq 100-\mathrm{mL}$ increase from baseline in trough $\mathrm{FEV}_{1}$ and corresponding odds ratio (OR), 95\% CI, and $p$-values.

\section{Results}

\subsection{Patient Characteristics}

The ITT population for the 12-week analysis of parallel design studies included 2246 patients assigned to 
UMEC/VI and 528 patients assigned to placebo. Of these, $989(44 \%)$ patients in the UMEC/VI group and $214(41 \%)$ patients in the placebo group were $\geq 65$ years of age, and $209(9 \%)$ patients in the UMEC/VI group and $45(9 \%)$ patients in the placebo group were $\geq 75$ years of age.

The ITT population for the 24-week analysis included 1296 patients assigned to UMEC/VI and 280 assigned to placebo. Of these, $566(44 \%)$ and $106(38 \%)$, respectively, were $\geq 65$ years of age, and $116(9 \%)$ and $30(11 \%)$, respectively, were $\geq 75$ years of age. All patients in the 24-week integration analysis were also included in the 12-week integration analysis.

In the 12-week analysis of crossover trials, the UMEC/ VI ITT population included 472 patients, and the placebo ITT population 505 patients. Of these, $168(36 \%)$ and 188 $(37 \%)$, respectively, were $\geq 65$ years of age, and $31(7 \%)$ and $27(5 \%)$, respectively, were $\geq 75$ years of age.

The baseline characteristics are summarized in Table 1 and were generally similar between UMEC/VI and placebo within each age category. Baseline $\mathrm{FEV}_{1}$ was highest in the $<65$-years age group (with mean values from each analysis ranging from 1274 to $1494 \mathrm{~mL}$ ) and lowest in the $\geq 75$-years age group (with mean values from each analysis ranging from 980 to $1093 \mathrm{~mL}$; Table 1).

\subsection{Trough FEV $_{1}$}

When considering absolute change from baseline, significantly greater improvements in trough $\mathrm{FEV}_{1}$ were observed following treatment with UMEC/VI compared with placebo in patients $<65$ or $\geq 65$ years of age across all analyses (12- and 24-week parallel design studies or 12-week crossover studies) and at all timepoints considered $(p<0.001$; Fig. 1 and Online Resource 2, see ESM). When comparing the effect of UMEC/VI against placebo in the $\geq 75$-year patient group, a statistically significant difference was observed in both parallel study datasets at all timepoints (12-week and 24-week groups; $p<0.001$ ). In the crossover analysis, significant differences in trough $\mathrm{FEV}_{1}$ between placebo and UMEC/VI were also observed in the $\geq 75$-year group at both Day 2 and Day 42 ( $p<0.001$ and $p=0.023$, respectively) but the difference was not statistically significant at Day $84(p=0.064)$ (Fig. 1 and Online Resource 2, see ESM).

When expressed as ratio to baseline (i.e., percentage change from baseline), UMEC/VI was associated with significantly greater improvements in trough $\mathrm{FEV}_{1}$ compared with placebo in all analyses, regardless of timepoint or age group considered ( $p \leq 0.018$; Fig. 2 and Online Resource 3, see ESM). In the 12-week parallel-group analysis, the adjusted percent increase with UMEC/VI compared with placebo at Day 84 was 15\% (95\% CI 12-18), $15 \%(95 \%$ CI 11-18), and $18 \%$ (95\% CI 10-26) in patients $<65, \geq 65$, and $\geq 75$ years of age, respectively (all $p<0.001$; Fig. 2). In the 24 -week parallel-group analysis, the adjusted percent increase with UMEC/VI compared with placebo at Day 169 was $16 \%$ (95\% CI 12-20), $17 \%$ (95\% CI $12-22)$ and $21 \%$ (95\% CI 11-33) in patients $<65, \geq 65$, and $\geq 75$ years of age, respectively (all $p<0.001$; Fig. 2). In the 12-week crossover analysis, the adjusted percent increase with UMEC/VI compared with placebo at Day 84 was $17 \%$ (95\% CI 15-19), $16 \%$ (95\% CI 13-19), and 9\% (95\% CI 2-18) in patients $<65, \geq 65$, and $\geq 75$ years of age, respectively ( $p \leq 0.018$; Fig. 2). Trough FEV $_{1}$ LS mean percent change from baseline and adjusted differences between treatments for other timepoints for all three analyses are shown in Online Resource 3 (see ESM).

\subsection{FEV $_{1}$ Responder Analysis}

The proportion of $\mathrm{FEV}_{1}$ responders (patients with $\mathrm{a} \geq$ 100 - $\mathrm{mL}$ increase from baseline in trough $\mathrm{FEV}_{1}$ ) was significantly greater with UMEC/VI compared with placebo regardless of age group or analysis (12- and 24-week parallel design studies or 12-week crossover studies) at all timepoints considered ( $p \leq 0.005$; Fig. 3 and Online Resource 4, see ESM). In the 12-week parallel-group analysis, the proportion of $\mathrm{FEV}_{1}$ responders in the UMEC/VI group at Day 84 was $61 \%, 58 \%$, and $57 \%$ with OR versus placebo of 3.47 (95\% CI 2.55-4.72), 5.42 (95\% CI 3.67-8.00), and 5.38 (95\% CI 2.31-12.56) in patients $<65, \geq 65$, and $\geq 75$ years of age, respectively (all $p<0.001$; Fig. 3 ). In the 24-week parallelgroup analysis, the proportion of $\mathrm{FEV}_{1}$ responders in the UMEC/VI group at Day 169 was 56\%, 55\%, and 48\% with OR versus placebo of 4.07 (95\% CI 2.65-6.25), 5.07 (95\% CI 2.96-8.69), and 4.86 (95\% CI 1.61-14.63) in patients $<65, \geq 65$, and $\geq 75$ years of age, respectively ( $p \leq 0.005$; Fig. 3). In the 12-week crossover analysis, the proportion of $\mathrm{FEV}_{1}$ responders to UMEC/VI therapy at Day 84 was 58\% and 53\% with OR versus placebo of 8.09 (95\% CI 5.31-12.32) and 5.79 (95\% CI 3.34-10.04) in patients $<65$ and $\geq 65$ years of age, respectively (all $p<0.001$; Fig. 3). OR for the subgroup of patients $\geq 75$ years of age could not be calculated in this analysis as the model did not converge due to the low number of patients in this subgroup (UMEC/VI: $n=31$; placebo: $n=27$ ). The proportion of $\mathrm{FEV}_{1}$ responders and corresponding OR $(95 \% \mathrm{CI})$ for other timepoints for all three analyses are shown in Online Resource 4 (see ESM).

\subsection{Safety}

The incidence of AEs and serious AEs was similar in the placebo and UMEC/VI groups for all age groups across all three analyses (Table 2). AEs occurring in five or more and two or more patients across both treatment arms and 
Table 1 Baseline characteristics by age group and analysis

\begin{tabular}{|c|c|c|c|c|c|c|}
\hline & \multicolumn{4}{|c|}{ Parallel design studies } & \multirow{2}{*}{\multicolumn{2}{|c|}{$\frac{\text { Crossover design studies }}{12 \text {-week analysis }}$}} \\
\hline & \multicolumn{2}{|c|}{ 12-week analysis } & \multicolumn{2}{|c|}{ 24-week analysis } & & \\
\hline & $\begin{array}{l}\text { Placebo } \\
(N=528)\end{array}$ & $\begin{array}{l}\text { UMEC/VI } \\
(N=2246)\end{array}$ & $\begin{array}{l}\text { Placebo } \\
(N=280)\end{array}$ & $\begin{array}{l}\text { UMEC/VI } \\
(N=1296)\end{array}$ & $\begin{array}{l}\text { Placebo } \\
(N=505)\end{array}$ & $\begin{array}{l}\text { UMEC/VI } \\
(N=472)\end{array}$ \\
\hline Age subgroup $<65$ years & $N=314$ & $N=1257$ & $N=174$ & $N=730$ & $N=317$ & $N=304$ \\
\hline Age (years), mean (SD) & $56.7(5.63)$ & $56.9(5.62)$ & $56.6(5.52)$ & $56.9(5.67)$ & $56.0(5.61)$ & $56.5(5.38)$ \\
\hline Gender (male), $n(\%)$ & $200(64)$ & $838(67)$ & $115(66)$ & $491(67)$ & $159(50)$ & $153(50)$ \\
\hline BMI $\left(\mathrm{kg} / \mathrm{m}^{2}\right)$, mean $(\mathrm{SD})$ & $27.52(6.077)$ & $27.55(6.097)$ & $27.52(6.077)$ & $27.47(6.357)$ & $27.62(6.037)$ & $27.50(5.950)$ \\
\hline Current smoker, $n(\%)$ & $201(64)$ & $791(63)$ & $118(68)$ & $472(65)$ & $233(74)$ & $233(73)$ \\
\hline $\begin{array}{l}\text { Smoking pack-years, mean } \\
\text { (SD) }\end{array}$ & $41.1(24.26)$ & $41.6(23.06)$ & $44.7(23.52)$ & $43.5(24.02)$ & $47.7(23.30)$ & $46.9(22.11)$ \\
\hline $\begin{array}{l}\text { Baseline } \mathrm{FEV}_{1}(\mathrm{~mL}) \text {, mean } \\
(\mathrm{SD})^{\mathrm{a}}\end{array}$ & $1360(548)$ & $1372(528)$ & $1274(497)$ & $1353(562)$ & $1494(469)$ & 1485 (497) \\
\hline Age subgroup $\geq 65$ years & $N=214$ & $N=989$ & $N=106$ & $N=566$ & $N=188$ & $N=168$ \\
\hline Age (years), mean (SD) & $70.7(4.75)$ & $70.9(4.68)$ & $71.6(5.07)$ & $70.8(4.59)$ & $70.5(4.52)$ & $70.7(4.54)$ \\
\hline Gender (male), $n(\%)$ & $144(67)$ & $726(73)$ & $80(75)$ & $412(73)$ & $119(63)$ & $105(63)$ \\
\hline BMI $\left(\mathrm{kg} / \mathrm{m}^{2}\right)$, mean $(\mathrm{SD})$ & $25.90(5.474)$ & $27.26(5.513)$ & $25.9(5.47)$ & $27.30(5.536)$ & $27.19(5.010)$ & $27.58(5.482)$ \\
\hline Current smoker, $n(\%)$ & $78(36)$ & $347(35)$ & $32(30)$ & $191(34)$ & $80(43)$ & $70(42)$ \\
\hline $\begin{array}{l}\text { Smoking pack-years, mean } \\
\text { (SD) }\end{array}$ & 45.9 (26.99) & $47.4(26.22)$ & $51.3(32.08)$ & $48.3(27.53)$ & $51.8(26.42)$ & $53.0(25.15)$ \\
\hline $\begin{array}{l}\text { Baseline } \mathrm{FEV}_{1}(\mathrm{~mL}) \text {, mean } \\
(\mathrm{SD})^{\mathrm{a}}\end{array}$ & $1111(447)$ & $1160(418)$ & $1078(390)$ & $1131(426)$ & $1234(417)$ & $1221(426)$ \\
\hline Age subgroup $\geq 75$ years & $N=45$ & $N=209$ & $N=30$ & $N=116$ & $N=27$ & $N=31$ \\
\hline Age (years), mean (SD) & $78.1(2.65)$ & $78.1(2.93)$ & $78.2(2.74)$ & $78.0(2.86)$ & $78.8(3.41)$ & $78.0(3.04)$ \\
\hline Gender (male), $n(\%)$ & $32(71)$ & $154(74)$ & $22(73)$ & $85(73)$ & $14(52)$ & $15(48)$ \\
\hline BMI $\left(\mathrm{kg} / \mathrm{m}^{2}\right)$, mean $(\mathrm{SD})$ & $25.72(6.244)$ & $25.66(4.405)$ & $25.72(6.244)$ & $25.35(4.252)$ & $27.12(4.382)$ & $26.34(4.937)$ \\
\hline Current smoker, $n(\%)$ & $13(29)$ & $45(22)$ & $8(27)$ & $24(21)$ & $19(70)$ & $22(71)$ \\
\hline $\begin{array}{l}\text { Smoking pack-years, mean } \\
\text { (SD) }\end{array}$ & 39.9 (21.77) & $48.0(25.3)$ & $43.4(21.71)$ & $48.0(26.26)$ & $54.2(33.50)$ & $49.5(30.00)$ \\
\hline $\begin{array}{l}\text { Baseline } \mathrm{FEV}_{1}(\mathrm{~mL}) \text {, mean } \\
(\mathrm{SD})^{\mathrm{a}}\end{array}$ & $1012(347)$ & $1093(402)$ & $980(364)$ & $1077(431)$ & $996(316)$ & $1051(350)$ \\
\hline
\end{tabular}

$B M I$ body mass index, $F E V_{l}$ forced expiratory volume in $1 \mathrm{~s}, S D$ standard deviation, $U M E C$ umeclidinium, $V I$ vilanterol ${ }^{\mathrm{a}}$ Mean of the two $\mathrm{FEV}_{1}$ assessments made 30 and 5 min pre-dose on Day 1

$\geq 3 \%$ of patients in either treatment arm are shown in Table 3 and Online Resource 5 (see ESM), respectively. Deaths occurred in $\leq 3 \%$ of patients in the UMEC/VI group and $<1 \%$ of patients in the placebo group (Table 2 ). There was no obvious trend in deaths in relation to age, and no fatal AEs were considered by investigators to be related to treatment.

\section{Discussion}

In the 12- and 24-week analyses of parallel design studies, UMEC/VI was consistently associated with significantly greater improvements in trough $\mathrm{FEV}_{1}$, in terms of absolute change (in $\mathrm{mL}$ ) and percent change from baseline, compared with placebo in all age groups $(<65, \geq 65$, and $\geq 75$ years $)$ and at all timepoints $(p<0.001)$. In the crossover analysis, which included studies performed in hyperinflated patients (resting functional residual capacity $\geq 120 \%$ of predicted), differences in improvements in trough $\mathrm{FEV}_{1}$ between UMEC/VI and placebo were also significant for all age groups and timepoints except for the $\geq 75$-year age group at Day 84. When expressed as percentage change from baseline, the improvements in trough $\mathrm{FEV}_{1}$ were significantly greater with UMEC/VI compared with placebo in all analyses across all age groups and timepoints. Consistent with these results, a significantly greater proportion of patients achieved a clinically 


\begin{tabular}{|c|c|c|c|c|c|c|}
\hline \multicolumn{7}{|c|}{ FEV $_{1}$ LS mean CFB $(\mathrm{mL})$ at Day $84-12$-week parallel design studies } \\
\hline \multirow[t]{2}{*}{ Age } & \multicolumn{3}{|c|}{ Placebo } & \multicolumn{3}{|c|}{ UMEC/VI } \\
\hline & $\mathbf{N}$ & $\mathbf{n}$ & LS mean CFB & $\mathbf{N}$ & $\mathbf{n}$ & LS mean CFB \\
\hline$<65$ years & 314 & 277 & 32 & 1253 & 1147 & 199 \\
\hline$\geq 65$ years & 214 & 183 & 5 & 988 & 892 & 169 \\
\hline$\geq 75$ years & 45 & 37 & -7 & 209 & 183 & 174 \\
\hline \multicolumn{7}{|c|}{ FEV $_{1}$ LS mean CFB $(\mathrm{mL})$ at Day $169-24$-week parallel design studies } \\
\hline \multirow[t]{2}{*}{ Age } & \multicolumn{3}{|c|}{ Placebo } & \multicolumn{3}{|c|}{ UMEC/VI } \\
\hline & $\mathbf{N}$ & $\mathbf{n}$ & LS mean CFB & $\mathbf{N}$ & $\mathbf{n}$ & LS mean CFB \\
\hline$<65$ years & 174 & 125 & 18 & 726 & 610 & 199 \\
\hline$\geq 65$ years & 106 & 76 & 11 & 565 & 458 & 196 \\
\hline$\geq 75$ years & 30 & 21 & -21 & 116 & 86 & 184 \\
\hline \multicolumn{7}{|c|}{$\mathrm{FEV}_{1}$ LS mean CFB (mL) at Day $84-12$-week crossover design studies } \\
\hline Age & $\mathbf{N}$ & $\mathbf{n}$ & LS mean CFB & $\mathbf{N}$ & $\mathbf{n}$ & LS mean CFB \\
\hline$<65$ years & 317 & 277 & -29 & 304 & 273 & 205 \\
\hline$\geq 65$ years & 188 & 154 & -31 & 168 & 148 & 150 \\
\hline$\geq 75$ years & 27 & 21 & 49 & 31 & 25 & 135 \\
\hline
\end{tabular}

Fig. 1 Absolute change from baseline in trough $\mathrm{FEV}_{1}$ by age group and analysis. $p$-values given for the adjusted difference (UMEC/VI minus placebo) in trough $\mathrm{FEV}_{1} \mathrm{LS}$ mean CFB. $C F B$ change from

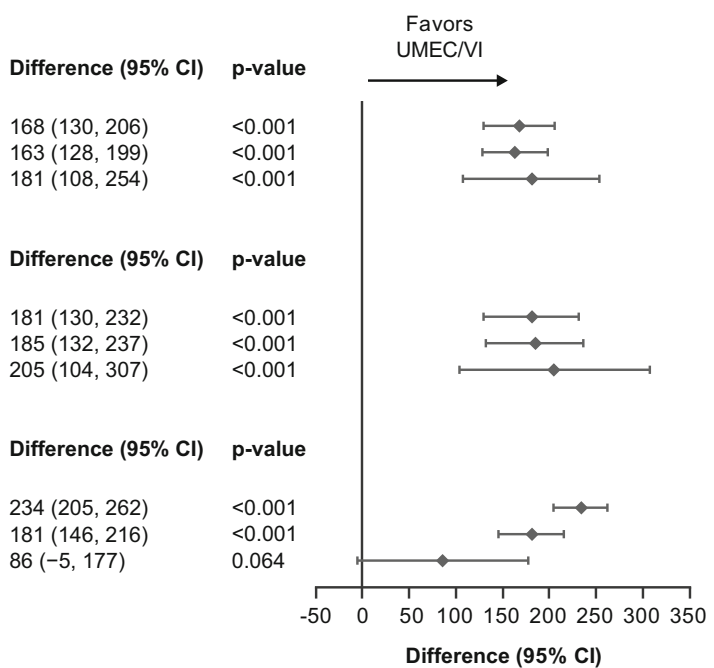

baseline, $C I$ confidence interval, $F E V_{l}$ forced expiratory volume in 1 s, $L S$ least squares, $n$ number of patients at each timepoint, $N$ total number of patients in subgroup, UMEC umeclidinium, VI vilanterol

\begin{tabular}{|c|c|c|c|c|c|c|}
\hline \multicolumn{7}{|c|}{$\mathrm{FEV}_{1}$ LS mean ratio to $\mathrm{BL}$ at Day 84 - 12-week parallel design studies } \\
\hline Age & $\mathbf{N}$ & $\mathbf{n}$ & LS mean ratio to $\mathrm{BL}$ & $\mathbf{N}$ & n & LS mean ratio to $\mathrm{BL}$ \\
\hline$<65$ years & 314 & 277 & 1.01 & 1253 & 1147 & 1.16 \\
\hline$\geq 65$ years & 214 & 183 & 1.01 & 988 & 892 & 1.16 \\
\hline$\geq 75$ years & 45 & 37 & 1.00 & 209 & 183 & 1.18 \\
\hline \multicolumn{7}{|c|}{$\mathrm{FEV}_{1}$ LS mean ratio to $\mathrm{BL}$ at Day $169-24$-week parallel design studies } \\
\hline \multirow{2}{*}{ Age } & \multicolumn{3}{|c|}{ Placebo } & \multicolumn{3}{|c|}{ UMEC/VI } \\
\hline & $\mathbf{N}$ & $\mathbf{n}$ & LS mean ratio to $B L$ & $\mathbf{N}$ & $\mathbf{n}$ & LS mean ratio to $B L$ \\
\hline$<65$ years & 174 & 125 & 1.01 & 726 & 610 & 1.16 \\
\hline$\geq 65$ years & 106 & 76 & 1.01 & 565 & 458 & 1.19 \\
\hline$\geq 75$ years & 30 & 21 & 0.98 & 116 & 86 & 1.20 \\
\hline \multicolumn{7}{|c|}{$\mathrm{FEV}_{1}$ LS mean ratio to $\mathrm{BL}$ at Day $84-12$-week crossover design studies } \\
\hline \multirow[t]{2}{*}{ Age } & \multicolumn{3}{|c|}{ Placebo } & \multicolumn{3}{|c|}{ UMEC/VI } \\
\hline & $\mathbf{N}$ & $\mathbf{n}$ & LS mean ratio to $B L$ & $\mathbf{N}$ & $\mathbf{n}$ & LS mean ratio to $B L$ \\
\hline$<65$ years & 317 & 277 & 0.98 & 304 & 273 & 1.14 \\
\hline$\geq 65$ years & 188 & 154 & 0.97 & 168 & 148 & 1.12 \\
\hline$\geq 75$ years & 27 & 21 & 1.04 & 31 & 25 & 1.13 \\
\hline
\end{tabular}

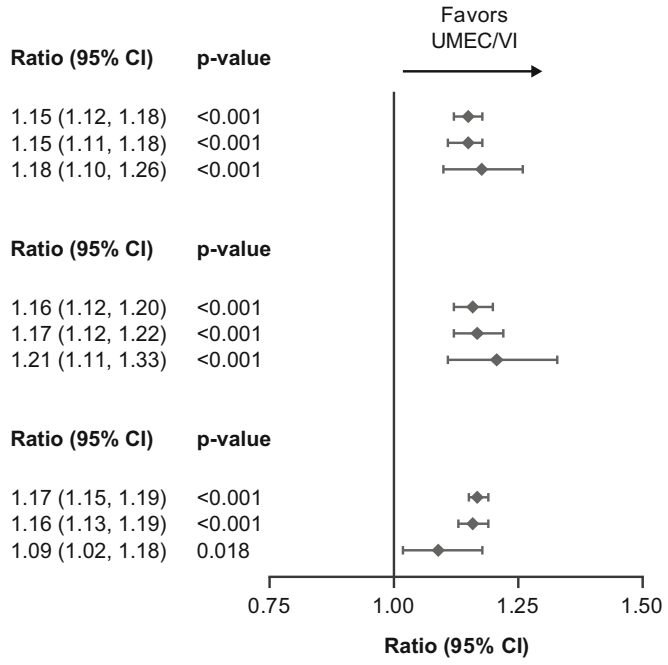

$F E V_{l}$ forced expiratory volume in $1 \mathrm{~s}, L S$ least squares, $n$ number of patients at each timepoint, $N$ total number of patients in subgroup, UMEC umeclidinium, $V I$ vilanterol

this was not the case in patients $\geq 75$ years of age, and instead an improvement in absolute trough $\mathrm{FEV}_{1}$ was seen in this subgroup of patients at Day 84. This improvement in trough $\mathrm{FEV}_{1}$ in patients who received placebo is likely to be an artefact of patient dropout in this small patient subgroup (22\% at Day 84 ), which may have contributed to the failure to detect a difference between treatments. The adjusted percent difference between treatments was also lowest at Day 84 in the 12-week crossover analysis in patients $\geq 75$ years of age, possibly for the same reasons noted above.

While some of the studies considered in this pooled analysis included active control groups as well as placebo, 


\begin{tabular}{|c|c|c|c|c|c|c|c|}
\hline \multicolumn{8}{|c|}{ FEV responders at Day $84-12$-week parallel design studies } \\
\hline \multirow{2}{*}{ Age } & \multicolumn{3}{|c|}{ Placebo } & \multicolumn{3}{|c|}{ UMEC/VI } & \multirow[t]{2}{*}{ OR $(95 \% \mathrm{Cl})$} \\
\hline & $\mathbf{N}$ & $\mathbf{n}$ & $\%$ & $\mathbf{N}$ & $\mathbf{n}$ & $\%$ & \\
\hline$<65$ years & 314 & 312 & 27 & 1253 & 1251 & 61 & $3.47(2.55,4.72)$ \\
\hline$\geq 65$ years & 214 & 214 & 20 & 988 & 983 & 58 & $5.42(3.67,8.00)$ \\
\hline$\geq 75$ years & 45 & 45 & 20 & 209 & 209 & 57 & $5.38(2.31,12.56)$ \\
\hline \multicolumn{8}{|c|}{ FEV responders at Day $169-24$-week parallel design studies } \\
\hline \multirow[t]{2}{*}{ Age } & \multicolumn{3}{|c|}{ Placebo } & \multicolumn{3}{|c|}{ UMEC/VI } & OR $(95 \% \mathrm{Cl})$ \\
\hline & $\mathbf{N}$ & $\mathbf{n}$ & $\%$ & $\mathbf{N}$ & $\mathbf{n}$ & $\%$ & \\
\hline$<65$ years & 174 & 174 & 20 & 726 & 725 & 56 & $4.07(2.65,6.25)$ \\
\hline$\geq 65$ years & 106 & 106 & 19 & 565 & 565 & 55 & $5.07(2.96,8.69)$ \\
\hline$\geq 75$ years & 30 & 30 & 17 & 116 & 116 & 48 & $4.86(1.61,14.63)$ \\
\hline \multicolumn{8}{|c|}{ FEV responders at Day $84-12$-week crossover design studies } \\
\hline \multirow[t]{2}{*}{ Age } & \multicolumn{3}{|c|}{ Placebo } & \multicolumn{3}{|c|}{ UMEC/VI } & OR $(95 \% \mathrm{Cl})$ \\
\hline & $\mathbf{N}$ & $\mathbf{n}$ & $\%$ & $\mathbf{N}$ & $\mathbf{n}$ & $\%$ & \\
\hline$<65$ years & 317 & 316 & 16 & 304 & 303 & 58 & $8.09(5.31,12.32)$ \\
\hline$\geq 65$ years & 188 & 188 & 16 & 168 & 167 & 53 & $5.79(3.34,10.04)$ \\
\hline
\end{tabular}

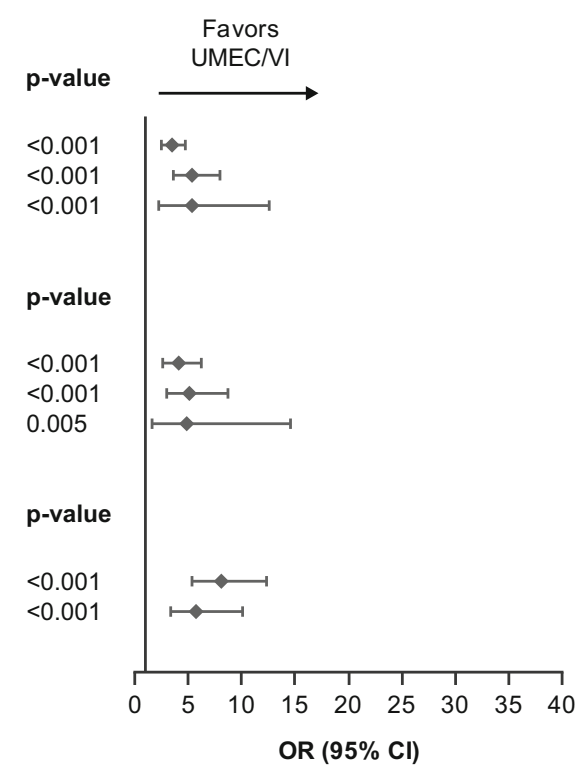

Fig. 3 Proportion of trough $\mathrm{FEV}_{1}$ responders by age group and analysis. In the 12-week crossover analysis, the model does not converge in the subgroup of patients $\geq 75$ years of age due to small patient numbers (placebo $n=27$; UMEC/VI $n=31$ ) and hence the OR from this group could not be calculated. $\mathrm{FEV}_{1}$ responders defined

the data presented here focused on the comparison between UMEC/VI and placebo to assess the consistency of the magnitude of improvement in lung function with increasing age with UMEC/VI, as well as its safety profile. As between-treatment differences would be larger for UMEC/ VI compared with placebo rather than with other active agents, the comparison with placebo presents the greatest opportunity to detect efficacy differences by age. COPD diagnosis in the elderly is associated with specific challenges, owing to the presence of comorbidities and the difficulty in performing spirometric assessments [36]. This in turn contributes to a potential under-diagnosis of the condition and its severity in this population, with as much as half of patients being undiagnosed, and therefore untreated [36]. This pooled analysis shows that, compared with placebo, UMEC/VI therapy is associated with a trend for larger percentage improvements and greater response rates in lung function benefits with increasing age, with a similar safety profile, and could therefore be of significant benefit in elderly patients with symptomatic COPD.

The aging population is increasing, and this will impact the total number of individuals with COPD, as well as the number of elderly people with COPD, which is likely to have a substantial impact on direct and indirect healthcare costs in the future [37]. Therefore, it is important that any new treatment for COPD is demonstrated to be effective and well tolerated in older individuals. Currently, the way that we define 'elderly' is largely arbitrary and based on age thresholds of 65 or 75 years, rather than degree of as increase from baseline in trough $\mathrm{FEV}_{1} \geq 100 \mathrm{~mL}$ at timepoint considered. $p$-values given for the responder analysis OR (UMEC/VI vs placebo). $C I$ confidence interval, $F E V_{l}$ forced expiratory volume in $1 \mathrm{~s}, n$ number of patients at each timepoint, $N$ total number of patients in subgroup, $O R$ odds ratio, $U M E C$ umeclidinium, $V I$ vilanterol

frailty or other markers of biological aging. However, until the adoption of a well accepted measure or score for physiological (rather than chronological) age that is reported as a baseline demographic characteristic in clinical trials, it is likely that chronological age will continue to be used to define patients as elderly.

Lung function declines with age, and indeed in this pooled analysis we observed lower baseline trough $\mathrm{FEV}_{1}$ values in older patient groups. This may explain why absolute $(\mathrm{mL})$ improvements in trough $\mathrm{FEV}_{1}$ from baseline with UMEC/VI tended to be slightly lower in older patients compared with their younger counterparts (Fig. 1 and Online Resource 2, see ESM); however, percentage increases tended to be larger in patients with advancing age, as illustrated in Fig. 2 and Online Resource 3 (see ESM). In addition, previous studies have noted that COPD management in elderly populations is associated with specific challenges (e.g., difficulties with inhaler use, inability to generate the required inspiratory flow, cognitive impairment, difficulties in diagnosis owing to the presence of multiple comorbidities) $[4,9,17,36]$. Although data on inhaler use were not assessed, the overall findings of this analysis suggest that, in older patients, UMEC/VI is associated with similar or greater absolute $(\mathrm{mL})$ improvements in trough $\mathrm{FEV}_{1}$, and a trend for higher percent increases, versus younger patients, and highlight that UMEC/VI can be used with confidence in elderly patients with greater lung function impairment. Previous studies have shown that the ELLIPTA inhaler device used to deliver UMEC/VI 
Table 2 Safety endpoints by age group and analysis

\begin{tabular}{|c|c|c|c|c|c|c|}
\hline & \multicolumn{4}{|c|}{ Parallel design studies } & \multirow{2}{*}{\multicolumn{2}{|c|}{$\frac{\text { Crossover design studies }}{12 \text {-week analysis }}$}} \\
\hline & \multicolumn{2}{|c|}{ 12-week analysis } & \multicolumn{2}{|c|}{ 24-week analysis } & & \\
\hline & $\begin{array}{l}\text { Placebo } \\
(N=528)\end{array}$ & $\begin{array}{l}\text { UMEC/VI } \\
(N=2246)\end{array}$ & $\begin{array}{l}\text { Placebo } \\
(N=280)\end{array}$ & $\begin{array}{l}\text { UMEC/VI } \\
(N=1296)\end{array}$ & $\begin{array}{l}\text { Placebo } \\
(N=505)\end{array}$ & $\begin{array}{l}\text { UMEC/VI } \\
(N=472)\end{array}$ \\
\hline Age subgroup $<65$ years & $N=314$ & $N=1257$ & $N=174$ & $N=730$ & $N=317$ & $N=304$ \\
\hline AEs & $122(39)$ & $506(40)$ & $89(51)$ & $348(48)$ & $96(30)$ & $91(30)$ \\
\hline Drug-related AEs & $12(4)$ & $42(3)$ & $11(6)$ & $35(5)$ & $6(2)$ & $7(2)$ \\
\hline Non-fatal SAEs & $11(4)$ & $44(4)$ & $6(3)$ & $31(4)$ & $7(2)$ & $8(3)$ \\
\hline Total deaths & $0(0)$ & $6(<1)$ & $0(0)$ & $4(<1)$ & $0(0)$ & $2(<1)$ \\
\hline $\begin{array}{l}\text { Treatment-related } \\
\text { deaths }\end{array}$ & $0(0)$ & $0(0)$ & $0(0)$ & $0(0)$ & $0(0)$ & $0(0)$ \\
\hline Age subgroup $\geq 65$ years & $N=214$ & $N=989$ & $N=106$ & $N=566$ & $N=188$ & $N=168$ \\
\hline AEs & $86(40)$ & $425(43)$ & $44(42)$ & $306(54)$ & $66(35)$ & $56(33)$ \\
\hline Drug-related AEs & $14(7)$ & $47(5)$ & $8(8)$ & $36(6)$ & $9(5)$ & $5(3)$ \\
\hline Non-fatal SAEs & $11(5)$ & $52(5)$ & $3(3)$ & $33(6)$ & $8(4)$ & $5(3)$ \\
\hline Total deaths & $0(0)$ & $5(<1)$ & $0(0)$ & $3(<1)$ & $1(<1)$ & $1(<1)$ \\
\hline $\begin{array}{l}\text { Treatment-related } \\
\text { deaths }\end{array}$ & $0(0)$ & $0(0)$ & $0(0)$ & $0(0)$ & $0(0)$ & $0(0)$ \\
\hline Age subgroup $\geq 75$ years & $N=45$ & $N=209$ & $N=30$ & $N=116$ & $N=27$ & $N=31$ \\
\hline AEs & $21(47)$ & $95(45)$ & $15(50)$ & $72(62)$ & $9(33)$ & $12(39)$ \\
\hline Drug-related AEs & $3(7)$ & $9(4)$ & $1(3)$ & $7(6)$ & $3(11)$ & $1(3)$ \\
\hline Non-fatal SAEs & $1(2)$ & $18(9)$ & $1(3)$ & $10(9)$ & $1(4)$ & $2(6)$ \\
\hline Total deaths & $0(0)$ & $1(<1)$ & $0(0)$ & $1(<1)$ & $0(0)$ & $1(3)$ \\
\hline $\begin{array}{l}\text { Treatment-related } \\
\text { deaths }\end{array}$ & $0(0)$ & $0(0)$ & $0(0)$ & $0(0)$ & $0(0)$ & $0(0)$ \\
\hline
\end{tabular}

Data expressed as $n(\%)$

$A E s$ adverse events, SAE serious adverse events, UMEC umeclidinium, VI vilanterol

has low-to-moderate resistance and is therefore able to deliver therapeutic doses of medication across a range of inspiratory flow rates, including in patients with very severe COPD [38, 39].

Encouragingly, in this pooled analysis, AE profiles were similar between the $<65$ years, $\geq 65$ years, and $\geq 75$ years age groups. This suggests that UMEC/VI has an acceptable safety profile in elderly populations, and that there are no specific concerns about increased risk of AEs with UMEC/VI as patients age. This is important because elderly patients may be particularly susceptible to AEs [9]. For example, antimuscarinic agents can cause dry mouth, and potentially result in acute urinary retention in elderly patients [9], while $\beta_{2}$-agonists may cause tremor, tachycardia, or hypokalemia [40]. Not only can these AEs cause considerable harm to the patient, but they also substantially increase the cost of care for elderly people [41]. The balance between treatment efficacy and safety in elderly patients is further complicated by polypharmacy [9, 25]. Data from the US suggest that about one in five communitydwelling elderly people are receiving a drug for one chronic condition that could adversely affect benefit from another drug (e.g., a nonselective $\beta$-blocker for hypertension that could counteract a $\beta$-agonist for COPD) [42].

Our study is not without limitations. First, the study was a post hoc analysis of previously published studies. Since the studies in this analysis were all randomized controlled trials, selection bias may have focused the patient populations on healthy, older patients with COPD [11], and not completely reflect the range of comorbidities seen among elderly patients with COPD in clinical practice. Indeed, as previously noted, elderly patients may be poorly represented in clinical trials as they may be indirectly excluded owing to increased levels or severity of comorbidities, difficulties in obtaining reliable spirometry results, or challenges in achieving compliance with study procedures $[15,16]$. Therefore, external validity remains an issue with this analysis and the findings of a favorable efficacy/safety balance of UMEC/VI in older and younger patients in our study should be confirmed in an observational clinical practice setting. Second, although the studies had no upper age limit, the number of patients in the oldest studied age 
Table 3 Adverse events occurring in five or more patients across both treatment arms and $\geq 3 \%$ of patients in either treatment arm by age and analysis

\begin{tabular}{|c|c|c|c|c|c|c|}
\hline & \multicolumn{4}{|c|}{ Parallel design studies } & \multirow{2}{*}{\multicolumn{2}{|c|}{$\frac{\text { Crossover design studies }}{12 \text {-week analysis }}$}} \\
\hline & \multicolumn{2}{|c|}{ 12-week analysis } & \multicolumn{2}{|c|}{ 24-week analysis } & & \\
\hline & $\begin{array}{l}\text { Placebo } \\
(N=528)\end{array}$ & $\begin{array}{l}\text { UMEC/VI } \\
(N=2246)\end{array}$ & $\begin{array}{l}\text { Placebo } \\
(N=280)\end{array}$ & $\begin{array}{l}\text { UMEC/VI } \\
(N=1296)\end{array}$ & $\begin{array}{l}\text { Placebo } \\
(N=505)\end{array}$ & $\begin{array}{l}\text { UMEC/VI } \\
(N=472)\end{array}$ \\
\hline $\begin{array}{l}\text { Age } \\
\text { subgroup }<65 \text { years }\end{array}$ & $N=314$ & $N=1257$ & $N=174$ & $N=730$ & $N=317$ & $N=304$ \\
\hline Headache & $28(9)$ & $109(9)$ & $21(12)$ & $67(9)$ & $9(3)$ & $3(<1)$ \\
\hline Viral URTI & $21(7)$ & $74(6)$ & $11(6)$ & $55(8)$ & $14(4)$ & $5(2)$ \\
\hline Back pain & - & - & $3(2)$ & $21(3)$ & - & - \\
\hline URTI & - & - & $7(4)$ & $15(2)$ & - & - \\
\hline Gastroenteritis & - & - & $5(3)$ & $4(<1)$ & - & - \\
\hline $\begin{array}{l}\text { Age } \\
\text { subgroup } \geq 65 \text { years }\end{array}$ & $N=169$ & $N=780$ & $N=106$ & $N=566$ & $N=188$ & $N=168$ \\
\hline Headache & $14(7)$ & $70(7)$ & $5(5)$ & $49(9)$ & $10(5)$ & $8(5)$ \\
\hline Viral URTI & $10(5)$ & $62(6)$ & $4(4)$ & $46(8)$ & $9(5)$ & $10(6)$ \\
\hline Back pain & $7(3)$ & $28(3)$ & $4(4)$ & $20(4)$ & - & - \\
\hline URTI & $11(5)$ & $18(2)$ & $9(8)$ & $16(3)$ & - & - \\
\hline Cough & - & - & $3(3)$ & $15(3)$ & - & - \\
\hline Oropharyngeal pain & $6(3)$ & $12(1)$ & - & - & - & - \\
\hline Hypertension & $7(3)$ & $11(1)$ & - & - & - & - \\
\hline Rhinitis & - & - & $3(3)$ & $5(<1)$ & - & - \\
\hline Sinusitis & - & - & - & - & $5(3)$ & $0(0)$ \\
\hline Dyspnea & - & - & $4(4)$ & $3(<1)$ & $5(3)$ & $3(2)$ \\
\hline Arthralgia & - & - & - & - & $2(1)$ & $5(3)$ \\
\hline $\begin{array}{l}\text { Age } \\
\text { subgroup } \geq 75 \text { years }\end{array}$ & $N=45$ & $N=209$ & $N=30$ & $N=116$ & $N=27$ & $N=31$ \\
\hline Headache & $3(7)$ & $17(8)$ & $2(7)$ & $11(9)$ & - & - \\
\hline Viral URTI & $3(7)$ & $12(6)$ & $3(10)$ & $9(8)$ & - & - \\
\hline Back pain & $2(4)$ & $8(4)$ & $0(0)$ & $6(5)$ & - & - \\
\hline Oropharyngeal pain & $2(4)$ & $3(1)$ & - & - & - & - \\
\hline
\end{tabular}

Data expressed as $n(\%)$

- indicates that the adverse event was not reported, or was reported in less than five patients across both treatment arms or $<3 \%$ in either treatment arm

UMEC umeclidinium, URTI upper respiratory tract infection, VI vilanterol

category ( $\geq 75$ years) was smaller, which may increase uncertainty in the precision of the results in this group. Nevertheless, the age range of the patient population included in this pooled analysis may provide reassurance that these results are applicable to elderly populations irrespective of the age thresholds used to define elderly. However, studies of longer duration may still be required to confirm that UMEC/VI efficacy is maintained during longterm treatment, particularly in hyperinflated elderly patients with COPD as recruited to the 12-week crossover studies. Finally, this analysis did not consider other clinically meaningful outcomes for the older population, such as symptoms and exercise capacity.

\section{Conclusions}

In this pooled analysis, UMEC/VI was associated with significant and clinically meaningful improvement in lung function, and a greater proportion of patients achieving clinically meaningful improvements in lung function, compared with placebo in all age groups $(<65, \geq 65$, and $\geq 75$ years), with no diminution of effect with advancing age. In addition, the safety profile of UMEC/VI was comparable in all age groups. These results indicate that dual bronchodilation with UMEC/VI via the ELLIPTA dry powder inhaler could substantially benefit elderly patients with COPD. 
Acknowledgements The authors would like to thank Lovemore Gakava (Statistician), contingent worker on assignment at GSK, Uxbridge, Middlesex, UK, for his contributions to the acquisition and analysis of the data presented in this manuscript.

\section{Compliance with Ethical Standards}

Ethical approval/informed consent All clinical studies included in this pooled analysis were carried out according to the principles of the Declaration of Helsinki and received appropriate ethical approval. Informed consent was obtained for all individual participants included in the studies used as the basis for this pooled analysis.

Conflict of interest RR, CC, IN, IB, DL, and MJA are employees of GSK and hold stocks and shares in GSK. LT is a contingent worker on assignment at GSK. ELLIPTA is owned by or licensed to the GlaxoSmithKline group of companies.

Funding This study was funded by GSK (GSK study number: 208125). Editorial support (in the form of writing assistance during development of the initial draft, assembling tables and figures, collating authors comments, grammatical editing, and referencing) was provided by Chrystelle Rasamison, at Fishawack Indicia Ltd, UK, and was funded by GSK.

Availability of Data The datasets generated during and/or analyzed during the current study are available from the corresponding author on reasonable request.

Open Access This article is distributed under the terms of the Creative Commons Attribution-NonCommercial 4.0 International License (http://creativecommons.org/licenses/by-nc/4.0/), which permits any noncommercial use, distribution, and reproduction in any medium, provided you give appropriate credit to the original author(s) and the source, provide a link to the Creative Commons license, and indicate if changes were made.

\section{References}

1. Adeloye D, Chua S, Lee C, Basquill C, Papana A, Theodoratou E, et al. Global and regional estimates of COPD prevalence: Systematic review and meta-analysis. J Glob Health. 2015;5(2):020415. https://doi.org/10.7189/jogh.05-020415.

2. Global Initiative for Chronic Obstructive Lung Disease. Global Strategy for the Diagnosis, Management and Prevention of Chronic Obstructive Pulmonary Disease. Updated 2018. http:// goldcopd.org/wp-content/uploads/2017/11/GOLD-2018-v6.0FINAL-revised-20-Nov_WMS.pdf. Accessed Jan 2018.

3. MacNee W, Rabinovich RA, Choudhury G. Ageing and the border between health and disease. Eur Respir J. 2014;44(5):1332-52. https://doi.org/10.1183/09031936.00134014.

4. Taffet GE, Donohue JF, Altman PR. Considerations for managing chronic obstructive pulmonary disease in the elderly. Clin Interv Aging. 2014;9:23-30. https://doi.org/10.2147/cia.s52999.

5. Afonso AS, Verhamme KM, Sturkenboom MC, Brusselle GG. COPD in the general population: prevalence, incidence and survival. Respir Med. 2011;105(12):1872-84. https://doi.org/10. 1016/j.rmed.2011.06.012.

6. Anecchino C, Rossi E, Fanizza C, De Rosa M, Tognoni G, Romero M, et al. Prevalence of chronic obstructive pulmonary disease and pattern of comorbidities in a general population. Int $\mathrm{J}$ Chron Obstruct Pulmon Dis. 2007;2(4):567-74.
7. Barnett K, Mercer SW, Norbury M, Watt G, Wyke S, Guthrie B. Epidemiology of multimorbidity and implications for health care, research, and medical education: a cross-sectional study. Lancet. 2012;380(9836):37-43. https://doi.org/10.1016/S0140-6736(12)602 40-2.

8. Haraguchi M, Nakamura H, Sasaki M, Miyazaki M, Chubachi S, Takahashi S, et al. Determinants of chronic obstructive pulmonary disease severity in the late-elderly differ from those in younger patients. BMC Res Notes. 2016;9:7. https://doi.org/10. 1186/s13104-015-1810-8.

9. Orvoen-Frija E, Benoit M, Catto M, Chambouleyron M, Duguet A, Emeriau JP, et al. Chronic obstructive pulmonary disease (COPD) in the elderly. Rev Mal Respir. 2010;27(8):855-73. https://doi.org/10.1016/j.rmr.2010.08.005.

10. Stallberg B, Janson C, Johansson G, Larsson K, Stratelis G, Telg $\mathrm{G}$, et al. Management, morbidity and mortality of COPD during an 11-year period: an observational retrospective epidemiological register study in Sweden (PATHOS). Prim Care Respir J. 2014;23(1):38-45. https://doi.org/10.4104/pcrj.2013.00106.

11. Kruis AL, Stallberg B, Jones RC, Tsiligianni IG, Lisspers K, van der Molen T, et al. Primary care COPD patients compared with large pharmaceutically-sponsored COPD studies: an UNLOCK validation study. PLoS One. 2014;9(3):e90145. https://doi.org/10. 1371/journal.pone.0090145.

12. Vestbo J, Leather D, Diar Bakerly N, New J, Gibson JM, McCorkindale S, et al. Effectiveness of fluticasone furoate-vilanterol for COPD in clinical practice. $\mathrm{N}$ Engl $\mathrm{J}$ Med. 2016;375(13):1253-60. https://doi.org/10.1056/NEJMoa1608033.

13. Niederseer D, Richter SA, Neunhauserer D, Lamprecht B, Buist SA, Studnicka M, et al. Symptomatic chronic obstructive pulmonary disease in clinical trials and in a population-based study. Sleep Breath. 2015;19(3):801-8. https://doi.org/10.1007/s11325014-1087-5.

14. Bourgeois FT, Olson KL, Tse T, Ioannidis JP, Mandl KD. Prevalence and characteristics of interventional trials conducted exclusively in elderly persons: a cross-sectional analysis of registered clinical trials. PLoS One. 2016;11(5):e0155948. https:// doi.org/10.1371/journal.pone.0155948.

15. Shenoy P, Harugeri A. Elderly patients' participation in clinical trials. Perspect Clin Res. 2015;6(4):184-9. https://doi.org/10. 4103/2229-3485.167099.

16. Bellia V, Pistelli R, Catalano F, Antonelli-Incalzi R, Grassi V, Melillo $G$ et al. Quality control of spirometry in the elderly. The SA.R.A. study. SAlute Respiration nell'Anziano $=$ Respiratory Health in the Elderly. Am J Respir Crit Care Med. 2000;161(4 Pt 1):1094-100. https://doi.org/10.1164/ajrccm.161.4.9810093.

17. Quinet P, Young CA, Heritier F. The use of dry powder inhaler devices by elderly patients suffering from chronic obstructive pulmonary disease. Ann Phys Rehabil Med. 2010;53(2):69-76. https://doi.org/10.1016/j.rehab.2009.11.001.

18. Yawn BP, Colice GL, Hodder R. Practical aspects of inhaler use in the management of chronic obstructive pulmonary disease in the primary care setting. Int $\mathrm{J}$ Chron Obstruct Pulmon Dis. 2012;7:495-502. https://doi.org/10.2147/COPD.S32674.

19. Turan O, Turan PA, Mirici A. Parameters affecting inhalation therapy adherence in elderly patients with chronic obstructive lung disease and asthma. Geriatr Gerontol Int. 2017;17(6):999-1005. https://doi.org/10.1111/ggi.12823.

20. Holguin F, Folch E, Redd SC, Mannino DM. Comorbidity and mortality in COPD-related hospitalizations in the United States, 1979 to 2001. Chest. 2005;128(4):2005-11. https://doi.org/10. 1378/chest.128.4.2005.

21. Melani AS, Bonavia M, Cilenti V, Cinti C, Lodi M, Martucci P, et al. Inhaler mishandling remains common in real life and is associated with reduced disease control. Respir Med. 2011;105(6):930-8. https://doi.org/10.1016/j.rmed.2011.01.005. 
22. Miller J, Edwards LD, Agusti A, Bakke P, Calverley PM, Celli B, et al. Comorbidity, systemic inflammation and outcomes in the ECLIPSE cohort. Respir Med. 2013;107(9):1376-84. https://doi. org/10.1016/j.rmed.2013.05.001.

23. Makela MJ, Backer V, Hedegaard M, Larsson K. Adherence to inhaled therapies, health outcomes and costs in patients with asthma and COPD. Respir Med. 2013;107(10):1481-90. https:// doi.org/10.1016/j.rmed.2013.04.005.

24. Mangoni AA, Jackson SHD. Age-related changes in pharmacokinetics and pharmacodynamics: basic principles and practice applications. Brit J Clin Pharmacol. 2003;57(1):6-14.

25. Fried TR, Vaz Fragoso CA, Rabow MW. Caring for the older person with chronic obstructive pulmonary disease. JAMA. 2012;308(12):1254-63. https://doi.org/10.1001/jama.2012.12422.

26. Horita N, Goto A, Shibata Y, Ota E, Nakashima K, Nagai K et al. Long-acting muscarinic antagonist (LAMA) plus long-acting beta-agonist (LABA) versus LABA plus inhaled corticosteroid (ICS) for stable chronic obstructive pulmonary disease (COPD). Cochrane Database Syst Rev. 2017;2:CD012066. https://doi.org/ 10.1002/14651858.cd012066.pub2.

27. Oba Y, Sarva ST, Dias S. Efficacy and safety of long-acting betaagonist/long-acting muscarinic antagonist combinations in COPD: a network meta-analysis. Thorax. 2016;71(1):15-25. https://doi.org/10.1136/thoraxjnl-2014-206732.

28. Decramer M, Anzueto A, Kerwin E, Kaelin T, Richard N, Crater $\mathrm{G}$, et al. Efficacy and safety of umeclidinium plus vilanterol versus tiotropium, vilanterol, or umeclidinium monotherapies over 24 weeks in patients with chronic obstructive pulmonary disease: results from two multicentre, blinded, randomised controlled trials. Lancet Respir Med. 2014;2(6):472-86. https://doi. org/10.1016/S2213-2600(14)70065-7.

29. Donohue JF, Maleki-Yazdi MR, Kilbride S, Mehta R, Kalberg C, Church A. Efficacy and safety of once-daily umeclidinium/vilanterol 62.5/25 mcg in COPD. Respir Med. 2013;107(10):1538-46. https:// doi.org/10.1016/j.rmed.2013.06.001.

30. Maleki-Yazdi MR, Kaelin T, Richard N, Zvarich M, Church A. Efficacy and safety of umeclidinium/vilanterol $62.5 / 25 \mathrm{mcg}$ and tiotropium $18 \mathrm{mcg}$ in chronic obstructive pulmonary disease: results of a 24-week, randomized, controlled trial. Respir Med. 2014;108(12):1752-60. https://doi.org/10.1016/j.rmed.2014.10. 002.

31. Donohue JF, Worsley S, Zhu CQ, Hardaker L, Church A. Improvements in lung function with umeclidinium/vilanterol versus fluticasone propionate/salmeterol in patients with moderate-to-severe COPD and infrequent exacerbations. Respir Med. 2015;109(7):870-81. https://doi.org/10.1016/j.rmed.2015.04.018.

32. Siler TM, Donald AC, O'Dell D, Church A, Fahy WA. A randomized, parallel-group study to evaluate the efficacy of umeclidinium/vilanterol $62.5 / 25 \mu \mathrm{g}$ on health-related quality of life in patients with COPD. Int $\mathrm{J}$ Chron Obstruct Pulmon Dis. 2016;11:971-9. https://doi.org/10.2147/COPD.S102962.

33. Maltais F, Singh S, Donald AC, Crater G, Church A, Goh AH, et al. Effects of a combination of umeclidinium/vilanterol on exercise endurance in patients with chronic obstructive pulmonary disease: two randomized, double-blind clinical trials. Ther Adv Respir Dis. 2014;8(6):169-81. https://doi.org/10.1177/ 1753465814559209.

34. Riley JH, Kalberg CJ, Donald A, Lipson DA, Shoaib M, Tombs L. Effects of umeclidinium/vilanterol on exercise endurance in COPD: a randomised study. ERJ Open Res. 2018. https://doi.org/ 10.1183/23120541.00073-2017.

35. Celli BR, MacNee W, Force AET. Standards for the diagnosis and treatment of patients with COPD: a summary of the ATS/ ERS position paper. Eur Respir J. 2004;23(6):932-46.

36. Incalzi RA, Scarlata S, Pennazza G, Santonico M, Pedone C. Chronic obstructive pulmonary disease in the elderly. Eur J Intern Med. 2014;25(4):320-8. https://doi.org/10.1016/j.ejim.2013.10.001.

37. Bustacchini S, Chiatti C, Furneri G, Lattanzio F, Mantovani LG. The economic burden of chronic obstructive pulmonary disease in the elderly: results from a systematic review of the literature. Curr Opin Pulm Med. 2011;17(Suppl 1):S35-41. https://doi.org/ 10.1097/01.mcp.0000410746.82840.79.

38. Hamilton M, Leggett R, Pang C, Charles S, Gillett B, Prime D. In vitro dosing performance of the $\operatorname{ELLIPTA}(\mathrm{R})$ dry powder inhaler using asthma and COPD patient inhalation profiles replicated with the electronic lung (eLung). J Aerosol Med Pulm Drug Deliv. 2015;28(6):498-506. https://doi.org/10.1089/jamp. 2015.1225.

39. Prime D, de Backer W, Hamilton M, Cahn A, Preece A, Kelleher $\mathrm{D}$, et al. Effect of disease severity in asthma and chronic obstructive pulmonary disease on inhaler-specific inhalation profiles through the ELLIPTA(R) dry powder inhaler. J Aerosol Med Pulm Drug Deliv. 2015;28(6):486-97. https://doi.org/10. 1089/jamp.2015.1224.

40. Akgun KM, Crothers K, Pisani M. Epidemiology and management of common pulmonary diseases in older persons. J Gerontol A Biol Sci Med Sci. 2012;67(3):276-91. https://doi.org/10.1093/ gerona/glr251.

41. Chiatti C, Bustacchini S, Furneri G, Mantovani L, Cristiani M, Misuraca $\mathrm{C}$, et al. The economic burden of inappropriate drug prescribing, lack of adherence and compliance, adverse drug events in older people: a systematic review. Drug safety. 2012;35(Suppl 1):73-87. https://doi.org/10.1007/BF03319105.

42. Lorgunpai SJ, Grammas M, Lee DS, McAvay G, Charpentier P, Tinetti ME. Potential therapeutic competition in community-living older adults in the U.S.: use of medications that may adversely affect a coexisting condition. PLoS One. 2014;9(2):e89447. https://doi.org/10.1371/journal.pone.0089447. 